\title{
Kinematic interaction factors of deep foundations with inclined piles *
}

\author{
Cristina Medina, Luis A. Padrón, Juan J. Aznárez, Ariel Santana, Orlando Maeso \\ Instituto Universitario de Sistemas Inteligentes y Aplicaciones Numéricas en Ingeniería \\ (SIANI) Universidad de Las Palmas de Gran Canaria \\ Edificio Central del Parque Científico y Tecnológico \\ Campus Universitario de Tafira, 35017, Las Palmas de Gran Canaria, Spain \\ \{cmedina,lpadron,jjaznarez,asantana,omaeso\}@ siani.es
}

16 April 2014

\begin{abstract}
The beneficial or detrimental role of battered piles on the dynamic response of piled foundations has not been yet fully elucidated. In order to shed more light on this aspect, kinematic interaction factors of deep foundations with inclined piles, are provided for single battered piles, as well as for $2 \times 2$ and $3 \times 3$ groups of piles subjected to vertically incident plane shear $\mathrm{S}$ waves. Piles are modelled as linear-elastic Bernoulli beams while soil is assumed to be a linear, isotropic, homogeneous viscoelastic half-space. Different pile group configurations, pile-soil stiffness ratios and rake angles are considered. The relevance and main trends observed in the influence of the rake angle on the kinematic interaction factors of the analysed foundations are inferred from the presented results. An important dependence of the kinematic interaction factors on the rake angle is observed together with the existence of an inclination angle at which cap rotation and excitation become out of phase in the low-to-mid frequency range. The existence of a small batter angle that provides minimum cap rotation is also shown.
\end{abstract}

\section{INTRODUCTION}

Inclined piles are frequently used in foundations that are expected to resist important lateral loads. Vertical piles transmit these loads only through shear and bending. However, raked piles have the ability of transmitting them primarily in axial compression and/or tension, which implies an increase of their lateral stiffness. Thus, when subjected to lateral loading, batter piles present generally smaller deformations and offer large bearing capacity than vertical piles of the same material and dimensions. Until 1990s, inclined piles were frequently used in seismic design of bridges and design of marginal wharfs and other port and harbour structures. However, the use of inclined piles became highly discouraged after the unsatisfactory seismic performance that deep foundations with battered piles showed during a series of earthquakes.

Until today, it has not been clarified whether the use of inclined piles has a detrimental or beneficial effect on the response of the superstructure or the foundation itself when submitted to seismic loads. Related studies have been conducted in order to identify the drawbacks and advantages of battered piles. Some authors $[1,2,3]$ developed numerical analyses that point to the larger axial loads along the pile shaft as well as to the increasing bending moment at the pile head as arguments to use vertical piles instead of inclined piles for seismic loads. Conversely, field evidence of the beneficial role of battered

${ }^{*}$ This is the peer reviewed version of the following article: Kinematic interaction factors of deep foundations with inclined piles, Earthquake Engineering and Structural Dynamics 2014; 43:2035-2050, which has been published in final form at http://onlinelibrary.wiley.com/doi/10.1002/eqe.2435/full. This article may be used for noncommercial purposes in accordance with Wiley Terms and Conditions for Self-Archiving. 
piles has been found both for the structure they support and the piles themselves [4,5]. These conclusions are in line with those inferred from different numerical analysis $[6,7,8]$.

Given that studies on the seismic response of battered piles have not yet fully elucidated their beneficial or detrimental role when submitted to dynamic loads, further research is needed. The contribution of this paper is related to the influence of inclined piles on the kinematic interaction factors of deep foundations.

Several studies have been carried out in relation with kinematic interaction factors of deep foundations using only vertical piles (see, for instance, $[9,10,11,12,13,14]$ ). An equivalent knowledge must be produced for configurations that include inclined piles, in order to provide the scientific and engineering communities with the kinematic interaction factors needed to accomplish substructuring analyses.

Up to the authors' knowledge, although other authors have accomplished analysis of the kinematic response of battered piles (e.g. [15, 3]), kinematic interaction factors of inclined piles have been presented only by Giannakou [16] for groups of $2 \times 1$ piles.

In this line, kinematic interaction factors of single inclined piles, as well as those of $2 \times 2$ and $3 \times 3$ groups with raked piles, embedded in a viscoelastic half-space, are presented in this paper. The relevance and main trends observed in the influence of the rake angle on the kinematic interaction factors of the analysed foundations are inferred from the presented results. A boundary element (BEM)- finite element (FEM) coupling formulation [17, 18, 19] has been used to obtain numerically these results. Piles are modelled directly using FEM as beams according to the Bernoulli hypothesis, while soil is modelled using BEM as a linear, isotropic, homogeneous, viscoelastic medium. Welded boundary contact conditions at the pile-soil interfaces are assumed and the pile heads are constrained by a rigid pile cap which is assumed to be free of contact with the soil. This formulation implies a reduction in terms of number of degrees of freedom in comparison with a pure multi-region boundary element method and provide accurate results at the same time.

\section{NUMERICAL MODEL}

A BEM-FEM coupling model is used in this work to compute the kinematic interaction factors of pile foundations. The dynamic response of the soil region is modelled by using a BEM formulation which considers the tractions at pile-soil interfaces as body forces acting within the domain. The stiffness of piles is introduced by longitudinal finite elements linking the internal nodes of the soil. The whole approach is depicted in Figure 1. The main advantage of this approach is that, being able to produce accurate results, it assumes that soil continuity is not altered by the presence of piles and, consequently, it is not necessary to discretize the pile-soil interfaces by boundary elements which considerably reduces the number of degrees of freedom in comparison with a pure multi-region boundary element approach. Moreover, the pile discretization is independent of the soil mesh which allows to use the same boundary mesh for all the pile-group configurations under investigation.
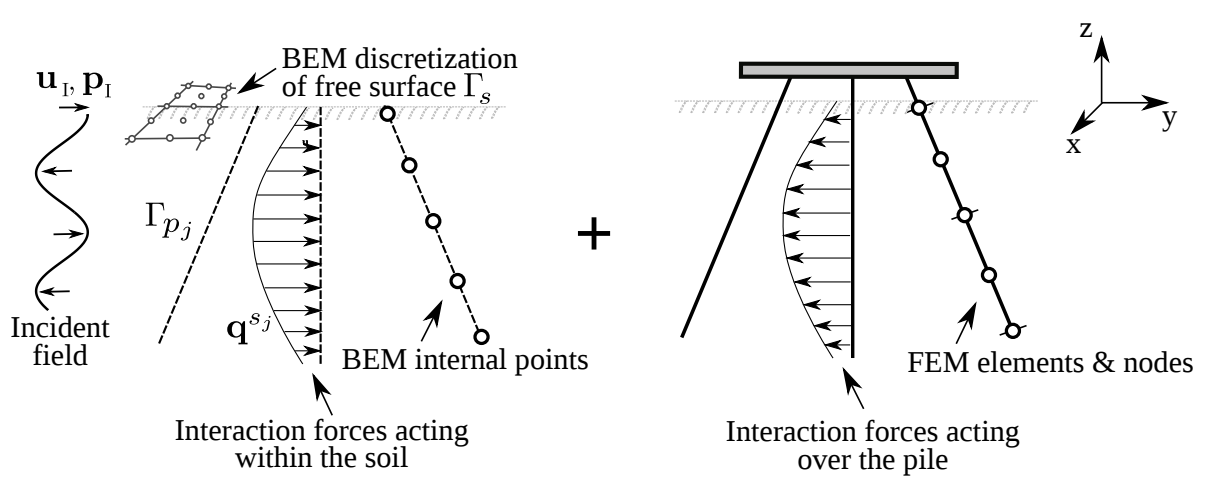

Figure 1: BEM-FEM model.

The soil is modelled by the BEM as a linear, homogeneous, isotropic, viscoelastic halfspace. Thus, 
the boundary integral equation for a time-harmonic elastodynamic state defined in this region with boundary $\Gamma_{s}$ can be expressed in a condensed and general form as

$$
\mathbf{c}^{k} \mathbf{u}^{k}+\int_{\Gamma_{s}} \mathbf{p}^{*} \mathbf{u} d \Gamma=\int_{\Gamma_{s}} \mathbf{u}^{*} \mathbf{p} d \Gamma+\sum_{j=1}^{n_{p}}\left[\int_{\Gamma_{p_{j}}} \mathbf{u}^{*} \mathbf{q}^{s_{j}} d \Gamma_{p_{j}}+\mathbf{\Upsilon}_{j}^{k} \mathbf{f}_{s_{j}}\right]
$$

where $\mathbf{c}^{k}$ is the local free term matrix at collocation point ' $k$ ', $\mathbf{u}$ and $\mathbf{p}$ are the displacement and traction fields in the three directions of space, $\mathbf{u}^{*}$ and $\mathbf{p}^{*}$ are the elastodynamic fundamental solution tensors representing the response to a harmonic concentrated load with a time variation $\mathrm{e}^{\mathrm{i} \omega t}$ (where $\omega$ is the circular frequency) applied at a point ' $k$ '. The second term of the right-hand side of Equation (1) represents the contribution of the internal loads. Thus, $n_{p}$ is the total number of load-lines (piles) and $\Gamma_{p_{j}}$ represents the pile-soil interface along the load line $j$ within the halfspace. $\mathbf{q}^{s_{j}}$ denotes the distribution of interaction loads along the pile shaft applied on a line defined by the pile axis, while $\mathbf{f}_{s_{j}}$ represents a point load placed at the tip of the pile. On the other hand, $\Upsilon_{j}^{k}$ represents the corresponding $\mathbf{u}^{*}$ tensor computed at the tip of the pile.

The boundary surface $\Gamma_{s}$ is discretized into quadratic elements of triangular and quadrilateral shapes with six and nine nodes, respectively. The displacement and traction fields $\mathbf{u}$ and $\mathbf{p}$, over each boundary element, is approximated in terms of their values at nodal points ( $\overline{\mathbf{u}}$ and $\overline{\mathbf{p}})$ making use of a set of polynomial interpolation functions [20]. On the other hand, the piles are modelled by FEM according to the Euler-Bernoulli hypothesis and are discretized into three-node beam elements in which the distribution of tractions $\mathbf{q}_{j}^{s}$ is approximated by the corresponding interpolation functions [17, 18] in terms of its values $\overline{\mathbf{q}}^{s_{j}}$ defined at a series of internal nodes. Now, Equation (1) can be written for all nodes in $\Gamma_{s}$ as a matrix equation of the type

$$
\mathbf{H}^{s s} \overline{\mathbf{u}}-\mathbf{G}^{s s} \overline{\mathbf{p}}-\sum_{j=1}^{n_{p}} \mathbf{G}^{s p_{j}} \overline{\mathbf{q}}^{s_{j}}-\sum_{j=1}^{n_{p}} \boldsymbol{\Upsilon}_{j}^{s_{j}} \mathbf{f}_{s_{j}}=0
$$

where $\mathbf{H}^{s s}$ and $\mathbf{G}^{s s}$ are coefficient matrices obtained by numerical integration over the boundary elements of the fundamental solution times the corresponding shape functions; and $\mathbf{G}^{s p_{j}}$ is the coefficient matrix obtained by numerical integration over load-line $j$ of the fundamental solution times the interpolation functions.

When seismic waves impinge on the site under study, reflection and refraction phenomena take place, and the arising wave field modifies the incident wave train. In this paper, the seismic excitation is assumed to be a harmonic plane $\mathrm{S}$ wave impinging the model from a far source. The wave field in the halfspace discretization $(\overline{\mathbf{u}})$ consists of two parts: the known incident field $\left(\overline{\mathbf{u}}_{I}\right)$ and the unknown scattered field ( $\left.\overline{\mathbf{u}}_{S}\right)$. The resulting displacement can be obtained by superposition as $\overline{\mathbf{u}}=\overline{\mathbf{u}}_{I}+\overline{\mathbf{u}}_{S}$. Thus, considering a pile foundation embedded in a soil subjected to incident waves, equation (2) can be written in terms of the scattered fields and expressed as

$$
\mathbf{H}^{s s} \overline{\mathbf{u}}-\sum_{j=1}^{n_{p}} \mathbf{G}^{s p_{j}} \overline{\mathbf{q}}^{s_{j}}-\sum_{j=1}^{n_{p}} \boldsymbol{\Upsilon}_{j}^{s} \mathbf{f}_{s_{j}}=\mathbf{H}^{s s} \overline{\mathbf{u}}_{I}
$$

where, taking into account the problem studied in this paper, the boundary conditions over the free surface $\Gamma_{s}$ nodes $(\overline{\mathbf{p}}=0)$ have been imposed.

Furthermore, Equation (1) can be also applied on internal nodes belonging to load-line $\Gamma_{p_{i}}$ in the same manner as for (3), yielding to the following matrix equation

$$
\overline{\mathbf{u}}^{p_{i}}+\mathbf{H}^{p_{i} s} \overline{\mathbf{u}}-\sum_{j=1}^{n_{p}} \mathbf{G}^{p_{i} p_{j}} \overline{\mathbf{q}}^{s_{j}}-\sum_{j=1}^{n_{p}} \mathbf{\Upsilon}_{j}^{p_{i}} \mathbf{f}_{s_{j}}=\overline{\mathbf{u}}_{I}^{p_{i}}+\mathbf{H}^{p_{i} s} \overline{\mathbf{u}}_{I}
$$

where $\overline{\mathbf{u}}^{p_{i}}$ is the vector of nodal displacements along load-line $i$.

On the other hand, the dynamic behaviour of pile $j$ in a finite element sense, can be described as:

$$
\left(\mathbf{K}_{j}-\omega^{2} \mathbf{M}_{j}\right) \overline{\mathbf{u}}_{j}^{p}=\mathbf{f}_{j}^{e x t}-\mathbf{Q}_{j} \overline{\mathbf{q}}^{s_{j}}
$$



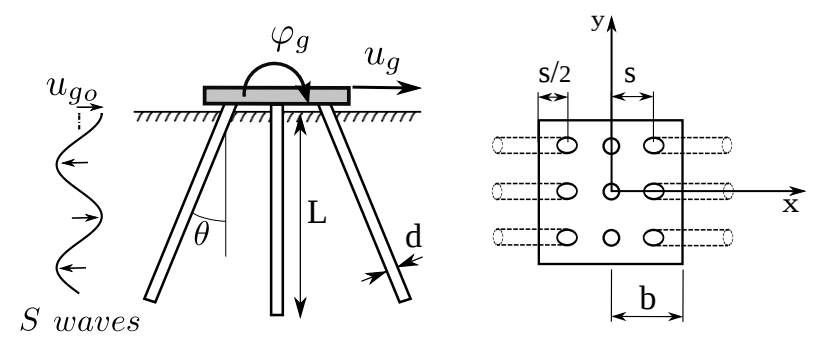

Figure 2: Pile foundation geometry.

where $\overline{\mathbf{u}}_{j}^{p}$ is the vector of nodal translation and rotation amplitudes along the pile, $\mathbf{f}_{j}^{\text {ext }}$ represents the punctual forces acting at the top and the tip of the pile and $\mathbf{Q}_{j}$ is the matrix that transforms the nodal tractions to equivalent nodal forces. $\mathbf{K}$ and $\mathbf{M}$ are the stiffness and mass matrices of the pile, respectively.

Imposing additional equations of equilibrium and compatibility by correlating BEM load lines and FEM piles, Equations (3), (4) and (5) can be rearranged in a system of equations representing the soil-pile foundation problem.

\section{GEOMETRICAL PARAMETERS AND PROBLEM DEFINITIONS}

All the configurations under study consist of piles arranged in square regular groups which are symmetrical with respect to planes $x z$ and $y z$ (see Figure 2). Pile heads are constrained (through fixed-head connection conditions) by a rigid pile cap which is assumed to be free of contact with the soil. Free head single piles are also studied. All piles have identical material and geometrical properties. Figure 2 illustrates the main geometrical parameters of the system: piles length $(L)$ and diameter $(d)$, spacing between centers of adjacent pile heads $(s)$, and rake angle between the vertical and the pile axis $(\theta)$. The foundation halfwidth is defined as $b=d$ for single piles, $b=s$ for $2 \times 2$ pile groups, and $b=3 s / 2$ for $3 \times 3$ pile groups. In this paper, the following properties are considered: piles slenderness ratio $L / d=15$, soil internal hysteretic damping coefficient $\beta_{s}=0.05$, soil Poisson's ratio $\nu_{s}=0.4$, soil-pile density ratio $\rho_{s} / \rho_{p}=0.7$, and pile soil modulus ratios $E_{p} / E_{s}=10^{3}$ (soft soil) and $E_{p} / E_{s}=10^{2}$ (stiff soil).

Translational and rotational kinematic interaction factors $I_{u}=u_{g} / u_{g_{o}}$ and $I_{\varphi}=\left(\varphi_{g} b\right) / u_{g_{o}}$, respectively, represents the horizontal $\left(u_{g}\right)$ and rocking $\left(\varphi_{g}\right)$ motions measured at the pile cap level and normalized with the free-field motion at the surface $u_{g_{o}}$. Both factors are functions of the dimensionless frequency $a_{o}=\omega d / c_{s}$. In this latter expression, $\omega$ is the excitation circular frequency and $c_{s}$ the speed of propagation of shear waves in the half-space.

\section{COMPARISON RESULTS}

The formulation described in Section 2 was impemented in a previously existent multi-region BEM FORTRAN code $[21,22]$. Its validity for obtaining kinematic interaction functions of vertical piles has been checked by comparing the obtained results with those provided by Kaynia and Novak [24] for a single pile, as well as for $3 \times 3$ groups of piles under vertically incident $S$ waves (see [18]).

This section addresses the validation of this BEM-FEM coupling formulation (as well as its implementation), for configurations including battered piles.

\subsection{D-boundary element formulation}

In order to assess the accuracy of the BEM-FEM formulation, described in Section 2, applied to the determination of kinematic interaction factors, results computed with this model are compared with those corresponding to the multi-region boundary element code [21]. 
This 3-D multi-region boundary element formulation, in which both soil and piles are modelled as continuum isotropic homogeneous linear viscoelastic regions with their actual geometries, is more rigorous and versatile than the simplified BEM-FEM used in this paper. However, it involves a greater number of degrees of freedom due to the fact that the pile-soil interface must also be discretized.

The boundary integral representation of the displacements in each region (soil and each pile) can be written as

$$
\mathbf{c}^{k} \mathbf{u}^{k}+\int_{\Gamma} \mathbf{p}^{*} \mathbf{u} d \Gamma=\int_{\Gamma} \mathbf{u}^{*} \mathbf{p} d \Gamma
$$

where $\mathbf{c}^{k}$ is the local free term matrix at collocation point ' $k$ ', $\mathbf{u}$ and $\mathbf{p}$ represent the displacement and traction fields in the three directions of space, and $\mathbf{u}^{*}$ and $\mathbf{p}^{*}$ are the elastodynamic fundamental solution tensors on the boundary $\Gamma$ due to a time-harmonic concentrated load at point ' $k$ '.

All boundaries are discretized into a finite number of quadratic elements of triangular and quadrilateral shapes with six and nine nodes, respectively. As in the BEM-FEM formulation, only one quarter of the geometry needs to be discretized due to the problem symmetries (see Figure 3).

In order to illustrate the application of this methodology to the problem at hand, a particular example will be developed in the next few lines. For the specific case of a single floating pile embedded in a viscoelastic half-space, writing equation (6) for each node of each region, yields the following matrix equations for pile and soil regions:

$$
\begin{gathered}
\mathbf{H}_{1}^{p} \mathbf{u}_{1_{S}}^{p}+\mathbf{H}_{2}^{p} \mathbf{u}_{2_{S}}^{p}=\mathbf{G}_{1}^{p} \mathbf{p}_{1_{S}}^{p}+\mathbf{G}_{2}^{p} \mathbf{p}_{2_{S}}^{p} \\
{\left[\begin{array}{cc}
\mathbf{H}_{2}^{p p} & \mathbf{H}_{2}^{p s} \\
\mathbf{H}_{3}^{s p} & \mathbf{H}_{3}^{s s}
\end{array}\right]\left[\begin{array}{l}
\mathbf{u}_{2_{S}} \\
\mathbf{u}_{3_{S}}
\end{array}\right]=\left[\begin{array}{ll}
\mathbf{G}_{2}^{p p} & \mathbf{G}_{2}^{p s} \\
\mathbf{G}_{3}^{s p} & \mathbf{G}_{3}^{s s}
\end{array}\right]\left[\begin{array}{l}
\mathbf{p}_{2_{S}} \\
\mathbf{p}_{3_{S}}
\end{array}\right]}
\end{gathered}
$$

where the sub-indexes $1-3$ correspond, respectively, to the pile connection with the rigid cap where tractions are null $\left(\Gamma_{1}\right)$, to the pile-soil interface $\left(\Gamma_{2}\right)$, and to the soil free-traction ground surface $\left(\Gamma_{3}\right)$. The sub-index $s$ indicates that the equations are written for the scattered field. Imposing external boundary conditions $\left(p_{1}^{p}=0\right.$ and $\left.p_{3}=0\right)$ together with compatibility $\left(\mathbf{u}_{2}^{p}=\mathbf{u}_{2}\right)$ and equilibrium $\left(\mathbf{p}_{2}^{p}=-\mathbf{p}_{2}\right)$ along the pile-soil interfaces, the combined equations for the kinematic interaction factors problem can be written as

$$
\left[\begin{array}{cccc}
\mathbf{H}_{1}^{p} & \mathbf{H}_{2}^{p} & \mathbf{G}_{2}^{p} & \mathbf{0} \\
\mathbf{0} & \mathbf{H}_{2}^{p p} & -\mathbf{G}_{2}^{p p} & \mathbf{H}_{2}^{p s} \\
\mathbf{0} & \mathbf{H}_{3}^{s p} & -\mathbf{G}_{3}^{s p} & \mathbf{H}_{3}^{s s}
\end{array}\right]\left[\begin{array}{c}
\mathbf{u}_{1} \\
\mathbf{u}_{2} \\
\mathbf{p}_{2} \\
\mathbf{u}_{3}
\end{array}\right]=\left[\begin{array}{cccc}
\mathbf{H}_{1}^{p} & \mathbf{H}_{2}^{p} & \mathbf{G}_{2}^{p} & \mathbf{0} \\
\mathbf{0} & \mathbf{H}_{2}^{p p} & -\mathbf{G}_{2}^{p p} & \mathbf{H}_{2}^{p s} \\
\mathbf{0} & \mathbf{H}_{3}^{s p} & -\mathbf{G}_{3}^{s p} & \mathbf{H}_{3}^{s s}
\end{array}\right]\left[\begin{array}{l}
\mathbf{u}_{1_{I}} \\
\mathbf{u}_{2_{I}} \\
\mathbf{p}_{2_{I}} \\
\mathbf{u}_{3_{I}}
\end{array}\right]
$$

\subsection{Validation results}

Figure 4 presents comparison results for several configurations of $2 \times 2$ inclined pile groups subjected to vertically incident $\mathrm{S}$ waves that, at free-field ground surface, causes motions in the direction of the

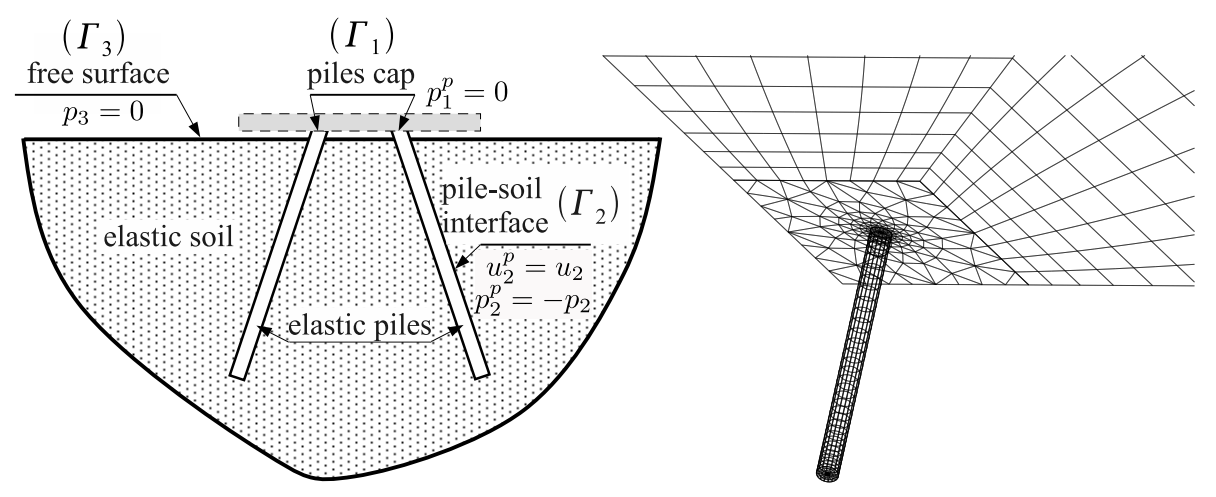

Figure 3: Multi-region boundary-element model definitions and BEM mesh. 

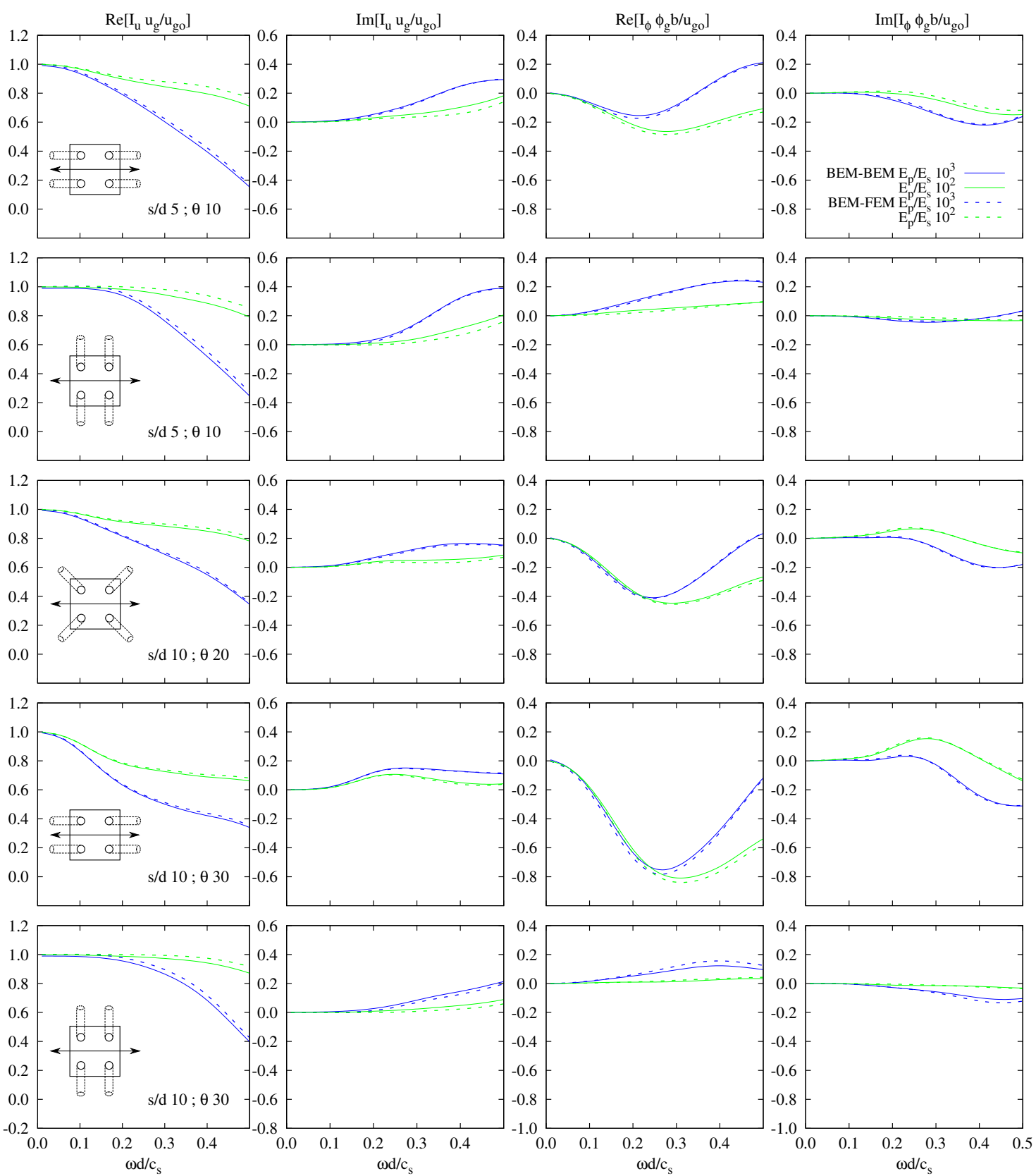

Figure 4: Kinematic interaction factors, $I_{u}$ and $I_{\varphi}$, of $2 \times 2$ pile groups with different spacing ratios $s / d$, rake angles $\theta$ and stiffness ratios $E_{p} / E_{s}$. Comparison between BEM-BEM and BEM-FEM.

$x$ axis. The first and the second rows of the plots correspond to a pile spacing ratio of $s / d=5$ and piles inclined, with a rake angle of $\theta=10^{\circ}$, parallel and perpendicular to the direction of the excitation, respectively. The third row shows the results corresponding to a pile spacing ratio of $s / d=10$ and piles inclined symmetrically along the cap diagonals with a rake angle of $\theta=20^{\circ}$. Finally, the fourth and fifth rows, present the results for a pile spacing ratio of $s / d=10$ and piles inclined, with a rake angle of $\theta=30^{\circ}$, parallel and perpendicular to the direction of the excitation, respectively. In all cases, results are obtained for two different pile-soil stiffness ratios.

The results corresponding to the BEM-FEM coupling formulation used in the following section are in strong agreement with those obtained from the more rigorous multi-domain boundary element (BEMBEM) code. The resulting relative errors, for a dimensionless frequency value $a_{o}=0.25$, for instance, are below $8 \%$ in terms of rotational kinematic interaction function $I_{\varphi}$, and below $3 \%$ in terms of transla- 
tional kinematic interaction function $I_{u}$. Therefore, the BEM-FEM formulation is the preferred method to carry out parametric studies, since it is more cost-effective.

\section{KINEMATIC INTERACTION FACTORS OF DEEP FOUNDATIONS WITH INCLINED PILES}

This section provides kinematic interaction factors of single inclined piles, and $2 \times 2$ and $3 \times 3$ pile groups with battered elements, according to the geometrical parameters and material properties defined in Section 3 and subjected to vertically-incident plane shear S waves. This study includes results corresponding to different pile groups configurations with piles inclined perpendicular or parallel to the direction of excitation as well as symmetrically along the cap diagonals. Four different rake angles have been considered: $\theta=0^{\circ}$ (vertical piles), $10^{\circ}, 20^{\circ}$ and $30^{\circ}$. Some vertical piles are included in $3 \times 3$ pile groups in order to maintain symmetry with respect to planes $x z$ and $y z$. Results corresponding to pile-soil stiffness ratios $E_{p} / E_{s}=1000$ (soft soil) and 100 (stiff soil) are presented. Stability and convergence analysis of the meshes have been performed in order to ensure the accuracy of the obtained results.

Figure 5 presents the translationtal kinematic interaction factors $I_{u}$ corresponding to free-head single inclined piles, together with the relative vertical displacements produced at the pile top by the incident field. When the pile is inclined parallel to the direction of the excitation (central column), $I_{u}$ decreases for increasing rake angles up to $a_{o}=0.5$ for $E_{p} / E_{s}=1000$, and up to $a_{o}=0.8$ for $E_{p} / E_{s}=100$. However, inclining the pile perpendicular to the direction of excitation (left column) has no beneficial effects in the low-frequency range and even shows a detrimental behaviour in the intermediate-frequency region as it leads to increasing values of the horizontal motion. For low values of $a_{o}, I_{u}$ increases for increasing pile-soil modulus ratios. The opposite occurs for high values of the dimensionless frequency. As expected, vertical displacements also grow for increasing rake angles, reaching displacements up to $60 \%$ of the horizontal free-field ground motion at $a_{o}=0.3$.

Figure 6 depicts the rotational kinematic interaction function $I_{\varphi}$ for the case defined above. For increasing rake angles, rotation slightly decreases for low-to-mid frequencies, and slightly increases for mid-to-high frequencies. Contrary to what could have been expected, the rotation is almost independent of the direction of inclination. In order to look into this fact, the deformed shapes of single piles, inclined in both directions, at $a_{o}=0.3$ are represented in Figure 7. It can be seen that the direction of inclination does influence significantly the pile behaviour as a whole, although the comparison between the undeformed and deformed shapes shows similar rotations in both configurations.

Figures 8, 10, 12 and 14 show the influence of rake angle on the translational kinematic interaction functions of four different configurations of pile groups. The low frequency region in which $I_{u}$ increases with frequency for single piles does not appear in the translational kinematic interaction function of pile groups, case in which $\left|I_{u}\right| \leq 1$ for all $a_{o}$. Inclining piles perpendicular to the direction of the excitation (left column) leads generally to higher values of $I_{u}$ in comparison with those obtained with vertical piles. Conversely, the use of piles inclined symmetrically along the cap diagonals (central column) generally results in a reduction of this motion in the low-to-mid frequency range. A stronger filtering of the seismic excitation can be achieved by inclining piles parallel to the direction of excitation (right column). The kinematic response of pile groups including battered piles is less sensitive to variations of the rake angle as the pile spacing ratio $s / d$ and the number of piles increases. In all cases, $I_{u}$ decreases for higher pile-soil modulus ratios for low-to-mid frequencies.

Figures 9,11, 13 and 15 present the rotational kinematic interaction factors for the pile groups under study in order to illustrate how the use of pile groups including battered piles influences the rocking motion at the pile cap. Higher pile spacing ratios $s / d$ or larger number of piles result in less cap rotation, though generally, this rotation increases with the rake angle. This effect is more pronounced when piles are inclined parallel to the direction of excitation. The more inclined, the more the pile works axially, that causes an axial displacement which in turn produces higher cap rotation. In fact, the maximum value of this rotation occurs at $a_{o} \approx 0.3$, which is the dimensionless frequency corresponding to the maximum value of the vertical displacement at the top of vertical single inclined piles (see right column of Figure 5). However, no relevant effects can be appreciated when inclining piles perpendicular to the 
direction of excitation. The dependence on the direction of inclination does not exist for single piles (see Figure 6), which suggests that it is the constraint imposed by the rigid pile cap which leads to changes in the dynamic behaviour of the foundation. Note that $b$ (used for the normalization of $I_{\varphi}$ ) changes for every configuration. When taking this into account, the absolute cap rotation strongly decreases with larger pile separations or number of piles.

Contrary to what occurs for vertical piles and even for single inclined piles, cap rotation and horizontal free-field ground motion become out of phase when inclining piles parallel to the direction of excitacion or simmetrically along the cap diagonals. This can be observed in the first row of Figures 9, 11, 13 and 15. For the purpose of illustrating this effect, Figure 16 shows the deformed shape at $a_{o}=0.3$ of $2 \times 2$ pile groups containing piles inclined parallel to the direction of excitation with four different rake angles (solid color lines), together with the undeformed shapes (dashed lines), and the deformed shape of the incident field $u_{g_{o}}$ (grey solid line). The response is qualitatively independent of the pile spacing ratio $s / d$. The lower the $E_{p} / E_{s}$ ratio, the better the pile compliance with the free-field motion.

The figures discussed above show a trend consisting in a monotonic increase of cap rotation at lowto-mid frequencies for higher rake angles. However, the observed change of phase suggests that this does not need to be the case. In order to analyse more closely the effects of rake angle on the rocking motion at the pile cap, Figure 17 shows the real part and the modulus of the rotational kinematic interaction factor of four different configurations with piles inclined parallel to the direction of excitation. Five different rake angles have been considered: $\theta=0^{\circ}$ (vertical piles), $1^{\circ}, 3^{\circ}, 5^{\circ}$, and $10^{\circ}$. It is worth to notice that the use of configurations with piles inclined a small rake angle (e.g. $\left.\theta=1^{\circ}, \theta=3^{\circ}\right)$ leads to a minimum rocking motion at the pile cap. This might represent a beneficial effect on the dynamic behaviour of slender structures, case in which the determination of an optimum rake angle for a minimum rocking input motion could be interesting.

The influence of pile-soil Young's modulus ratio and pile slenderness ratio $L / d$ on the rotational kinematic interaction factor has also been studied. Additional $L / d$ and $E_{p} / E_{s}$ ratios have been studied for some configurations but are not shown here for the sake of brevity. Contrary to what occurs for vertical piles, lower stiffness ratios $E_{p} / E_{s}$ (stiffer soils) lead to larger cap rotations. On the other hand, higher stiffness ratios (softer soils) result in an increase of the rake angle at which cap rotation and horizontal free-field ground surface motion become out of phase at low-to-mid frequencies. For instance, such an angle can reach values over $10^{\circ}$ for $E_{p} / E_{s}=5000$ (see Figure 16). Finally, it is worth noting that, when considering configurations with piles inclined parallel to the direction of excitation, higher pile slenderness ratios yield increasing rocking motions at the pile cap in a low frequency range, contrary to what occurs for vertical piles.

Besides kinematic interaction factors, the influence of rake angle on pile kinematic interaction forces is an important issue in the study of inclined piles subjected to SH waves. This is because the possibility of the development of large kinematic bending moments and shear forces when inclining the piles has resulted in a negative attitude towards batter piles (see [8]). In order to look also into this aspect of the problem, kinematic bending moments $M$ at pile heads are presented, for some configurations and vertically-incident $S$ waves producing unitary horizontal free-field motion at the ground surface, in terms of the pile maximum bending strain $\varepsilon_{p}$. Note that the axis around which such bending moments are measured is depicted in the corresponding figures. The advantages of representing $\varepsilon_{p}$ instead of $M$ are exposed in [25]. The relation between both parameters can be expressed as follows:

$$
\varepsilon_{p}=\frac{M}{E_{p} I_{p}} \frac{d}{2}
$$

being $I_{p}$ the pile cross-sectional moment of inertia.

The third row of Figures 9 and 11, illustrates how the variations of the rake angle affect the maximum bending strain of piles in configurations of $2 \times 2$ pile groups. When piles are inclined parallel to the direction of excitation (right column) or symmetrically along the cap diagonals (central column), the maximum bending strain increases with the rake angle for both low and high frequencies (in terms of the frequency range presented in the figures) when $s / d=5$, reaching an increment of up to $60 \%$ in the low frequency range (when $E_{p} / E_{s}=100$ ) with respect to the values corresponding to vertical piles. 

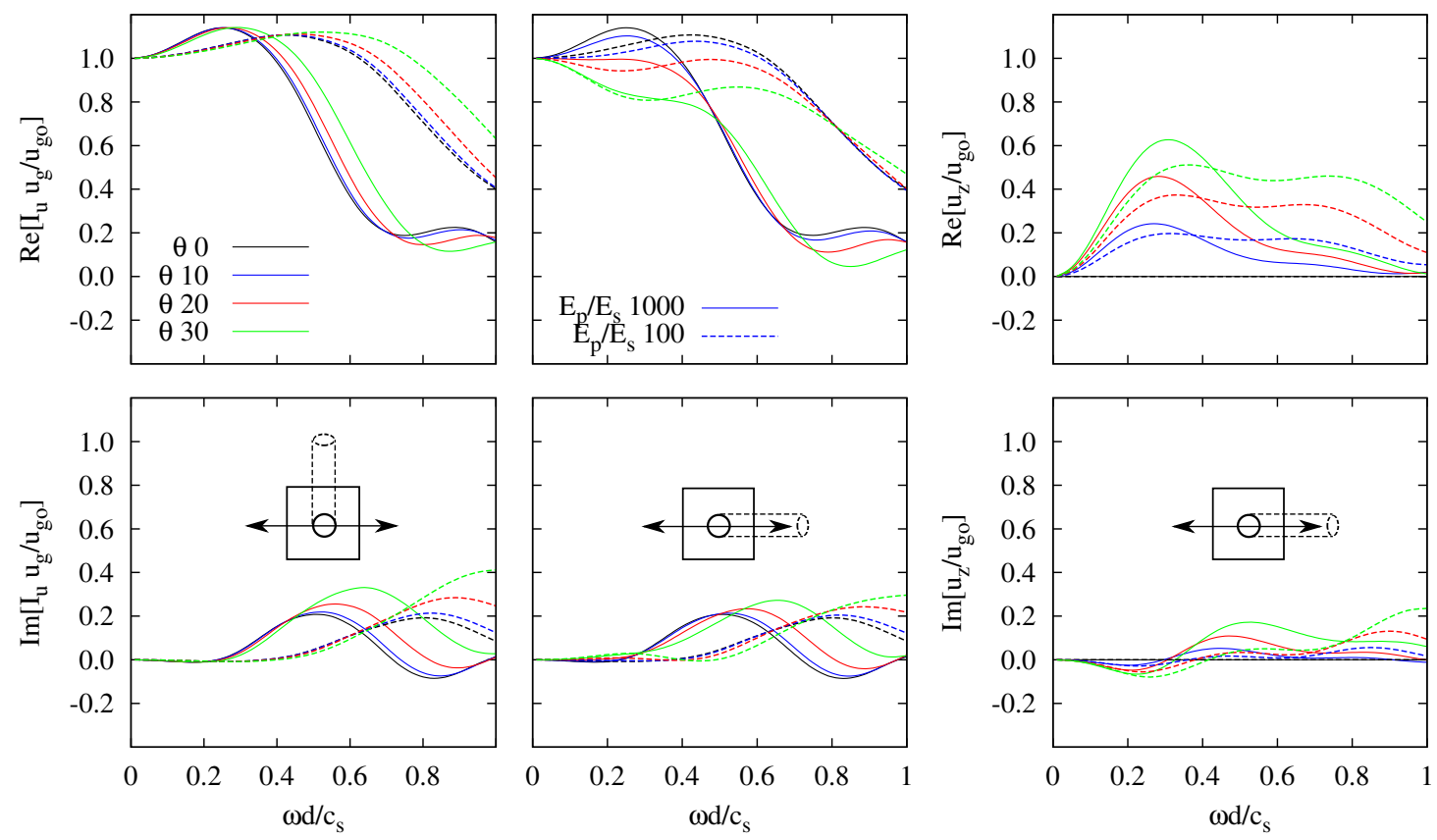

Figure 5: Translational kinematic interaction factor $I_{u}$ and vertical displacement $u_{z} / u_{g_{o}}$ of a single pile for different rake angles $\theta$.

Nevertheless, for intermediate frequencies the rake angle does not have a significant influence on the maximum bending strain. In those cases in which $E_{p} / E_{s}=1000$, the maximum bending strain reaches increments of up to $16 \%$ in the low frequency range. When $s / d=10$, maximum bending strain tends to increase with rake angle at mid-to-low frequencies but decreases at higher frequencies. On the other hand, in those cases in which piles are inclined perpendicular to the direction of excitation (left column), the maximum pile bending strain decreases as the rake angle increases for low-to-mid frequencies in all configurations. In short, in the mid-to-low frequency range maximum pile bending strains at pile heads tend to increase when piles are inclined parallel to the direction of the shaking; but tend to decrease when the piles are inclined perpendicular to such direction.

\section{CONCLUSIONS}

This paper presents kinematic interaction factors of single inclined piles, and $2 \times 2$ and $3 \times 3$ pile groups including battered elements embedded in a homogeneous viscoelastic half-space and subjected to vertically-incident plane shear $\mathrm{S}$ waves. The possibility of the development of large kinematic bending moments and shear forces when inclining the piles has resulted in a negative attitude towards batter piles (see [8]). In order to study the effect of rake angle on kinematic bending moments, maximum pile bending strain at pile heads are also presented for some cases. A boundary element-finite element formulation has been used to obtain numerical results for different soil properties, rake angles and configurations.

The main conclusions drawn from the analysis of the results obtained for the cases under study are summarised below:

- The ability of a deep foundation to filter the seismic input increases significantly if all or some of it members are inclined in the direction of shaking.

- The beneficial role of the pile inclination disappears at high frequencies.

- Both kinematic interaction factors strongly depends on the direction of inclination of piles. Deep 


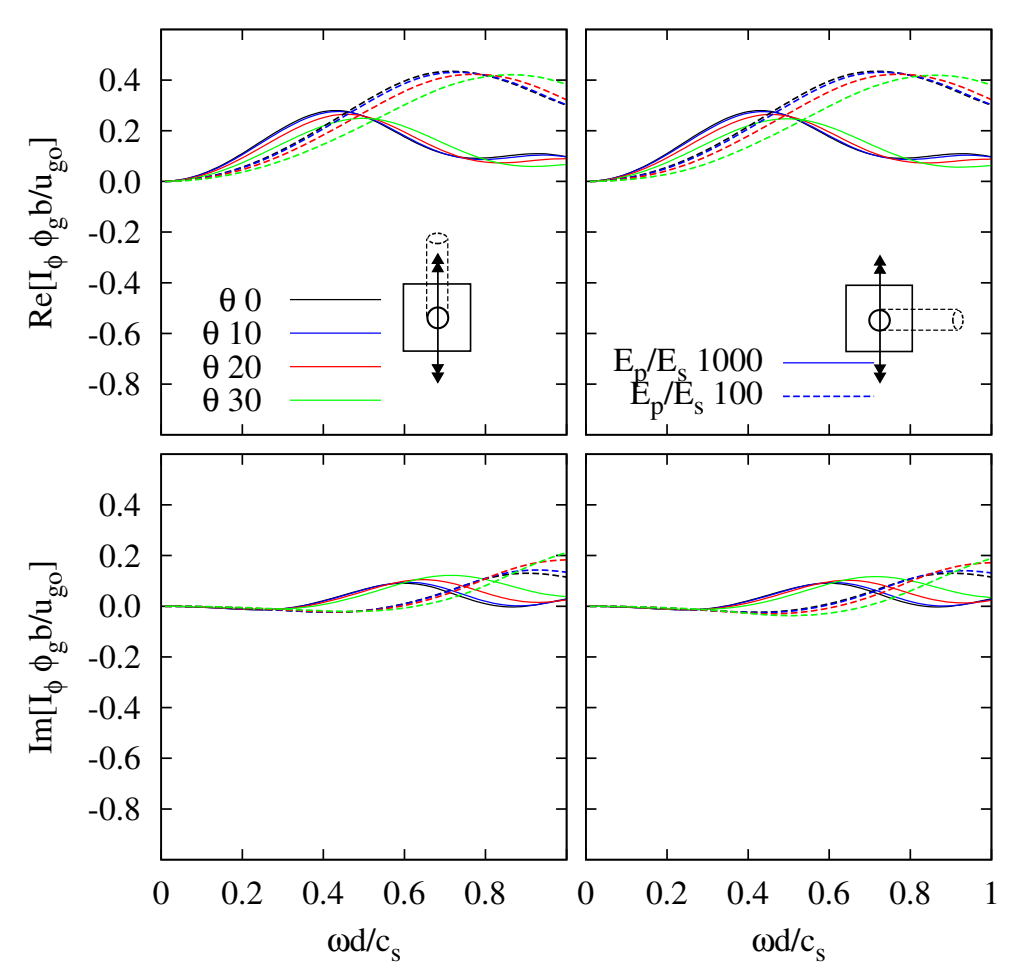

Figure 6: Rotational kinematic interaction factor $I_{\varphi}$ of a single pile for different rake angles $\theta$.
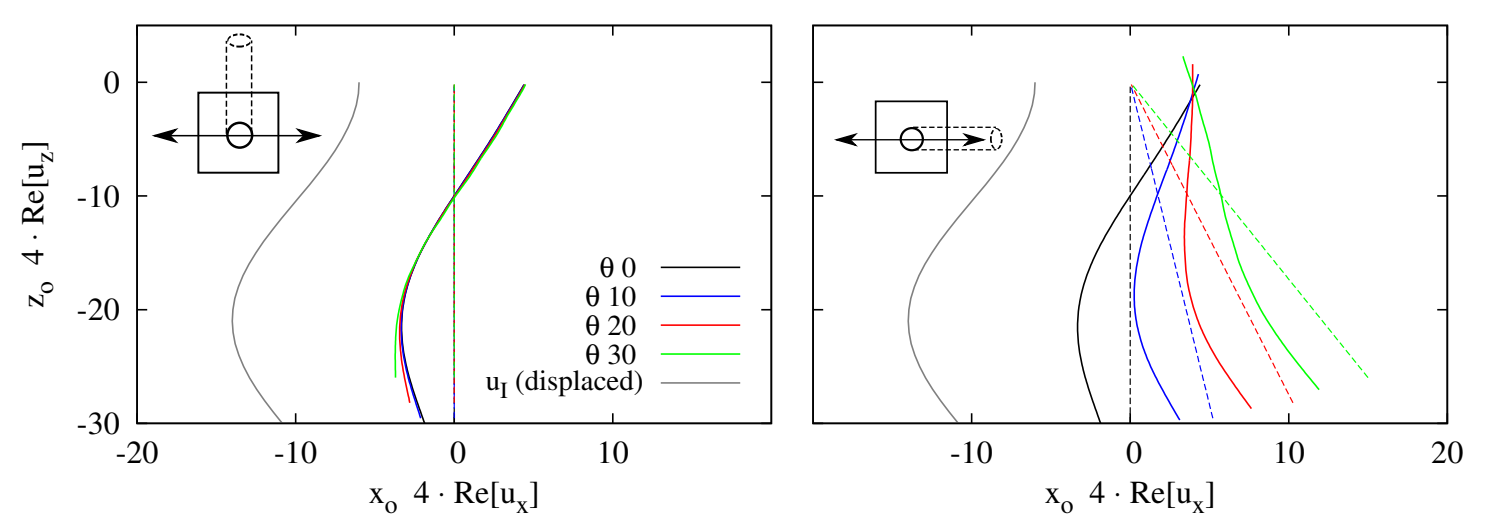

Figure 7: Deformed shape (solid line) and undeformed shape (dash line) of simple inclined piles with different rake angles $\theta$ considering $\left|u_{g_{o}}\right|=1\left(u_{I}\right.$ displaced 10 units to the left only for illustration purposes). $a_{o}=0.3 . E_{p} / E_{s}=1000$.

foundations including piles inclined perpendicular to the direction of excitation generally have a detrimental role in terms of horizontal motion.

- The rotational kinematic interaction factor $I_{\varphi}$ of battered single piles is almost independent of the rake angle.

- Cap rotation and horizontal free-field ground motion become out of phase when inclining piles parallel to the direction of excitation or symmetrically along the cap diagonals. This effect depend on the rake angle, as well as on the pile-soil Young's modulus ratio.

- There exists an optimum rake angle (usually small) for which a minimum rotational motion at 


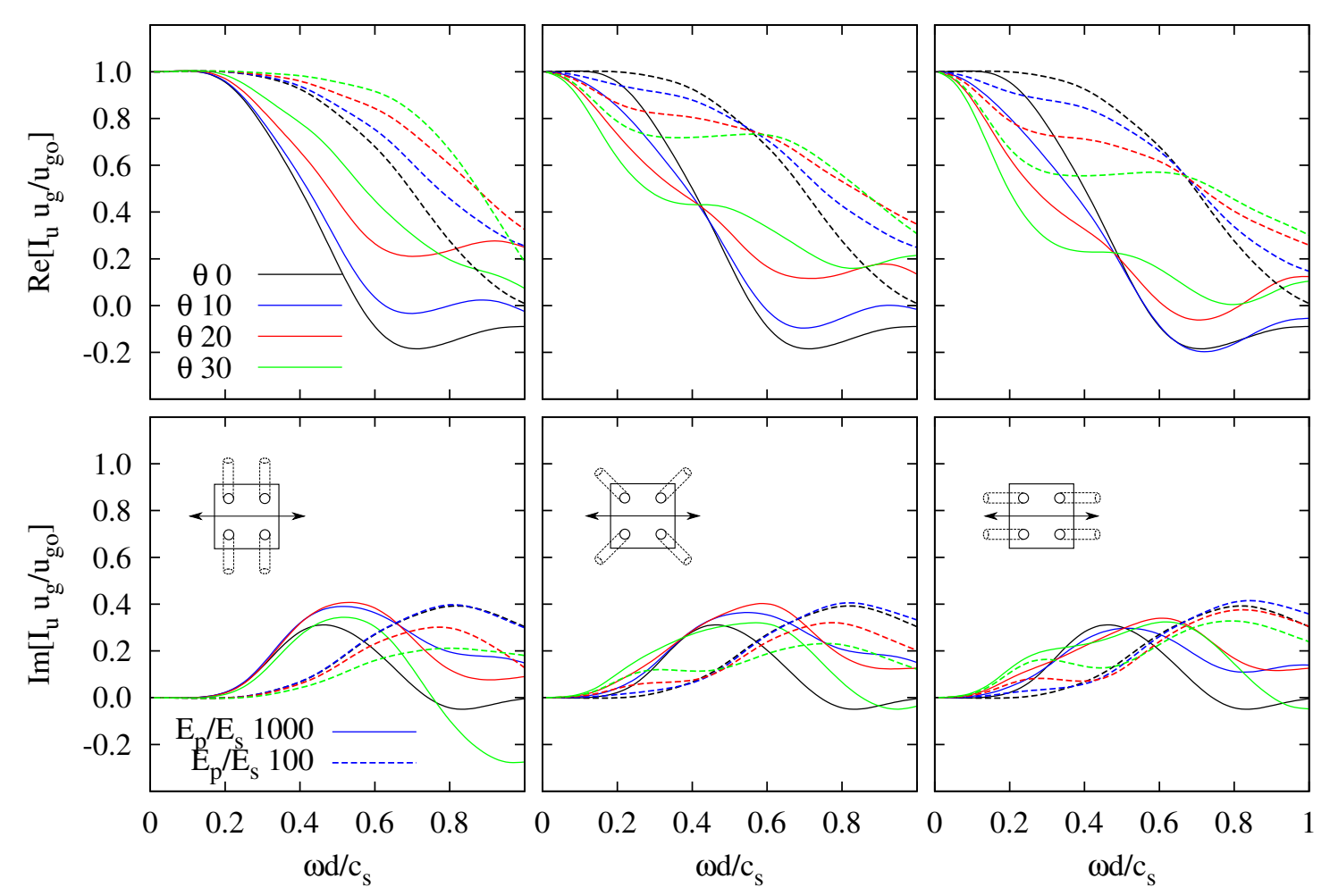

Figure 8: Translational kinematic interaction factor $I_{u}$ of a $2 \times 2$ pile group with battered piles with different rake angles $\theta$ and $s / d=5$.

pile cap is obtained in the low-to-mid frequency range. This phenomenon could be used in order to minimize the seismic input of a structure submitted to seismic loads although, in some cases, the realization of the optimum small rake angles could not be feasible. A monotonic trend of increasing cap rotation for increasing rake angles is observed for larger angles.

- Higher stiffness ratios (softer soils) result in an increase of the rake angle at which cap rotation and horizontal free-field ground surface motion become out of phase at low-to-mid frequencies.

- The kinematic response of pile groups including battered piles is less sensitive to variations of the rake angle as the pile spacing ratio $s / d$ or the number of piles increase.

- Lower stiffness ratios $E_{p} / E_{s}$ (stiffer soils) lead to higher cap rocking motions.

- Contrary to what occurs for vertical piles, a reduction of the pile slenderness ratio $L / d$ leads to decreasing values of the rocking motion at the pile cap, at least in a low frequency range, when considering configurations with piles inclined parallel to the direction of excitation.

- In the mid-to-low frequency range (usually the most important in the seismic design of deep foundations), maximum pile bending strains at pile heads tend to increase when piles are inclined parallel to the direction of the shaking; but tend to decrease when the piles are inclined perpendicular to such direction.

\section{ACKNOWLEDGEMENTS}

This work was supported by the Subdirección General de Proyectos de Investigación of the Ministerio de Economía y Competitividad (MINECO) of Spain and FEDER through research project BIA2010-21399C02-01 and also by the Agencia Canaria de Investigación, Innovación y Sociedad de la Información 

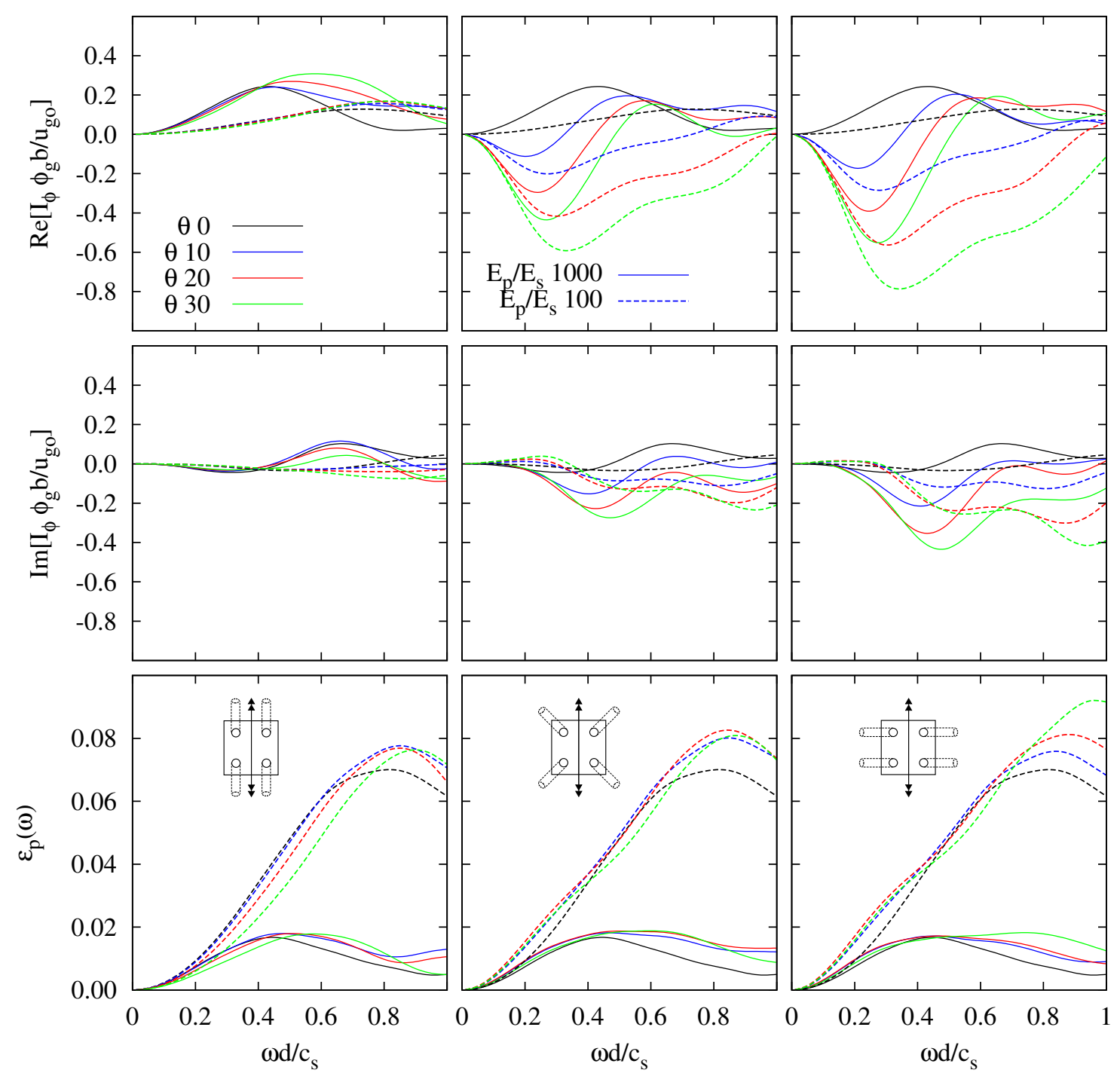

Figure 9: Rotational kinematic interaction factor $I_{\varphi}$ and maximum pile head bending strain $\varepsilon_{p}$ (considering $\left|u_{g_{o}}\right|=1$ ) of a $2 \times 2$ pile group with battered piles with different rake angles $\theta$ and $s / d=5$.

(ACIISI) of the Government of the Canary Islands and FEDER through research project ProID20100224. C. Medina is a recipient of a fellowship from the Program of predoctoral fellowships of the University of Las Palmas de Gran Canaria (ULPGC). The authors are grateful for this support. The authors would also like to thank the reviewers of the manuscript for their valuable suggestions. 

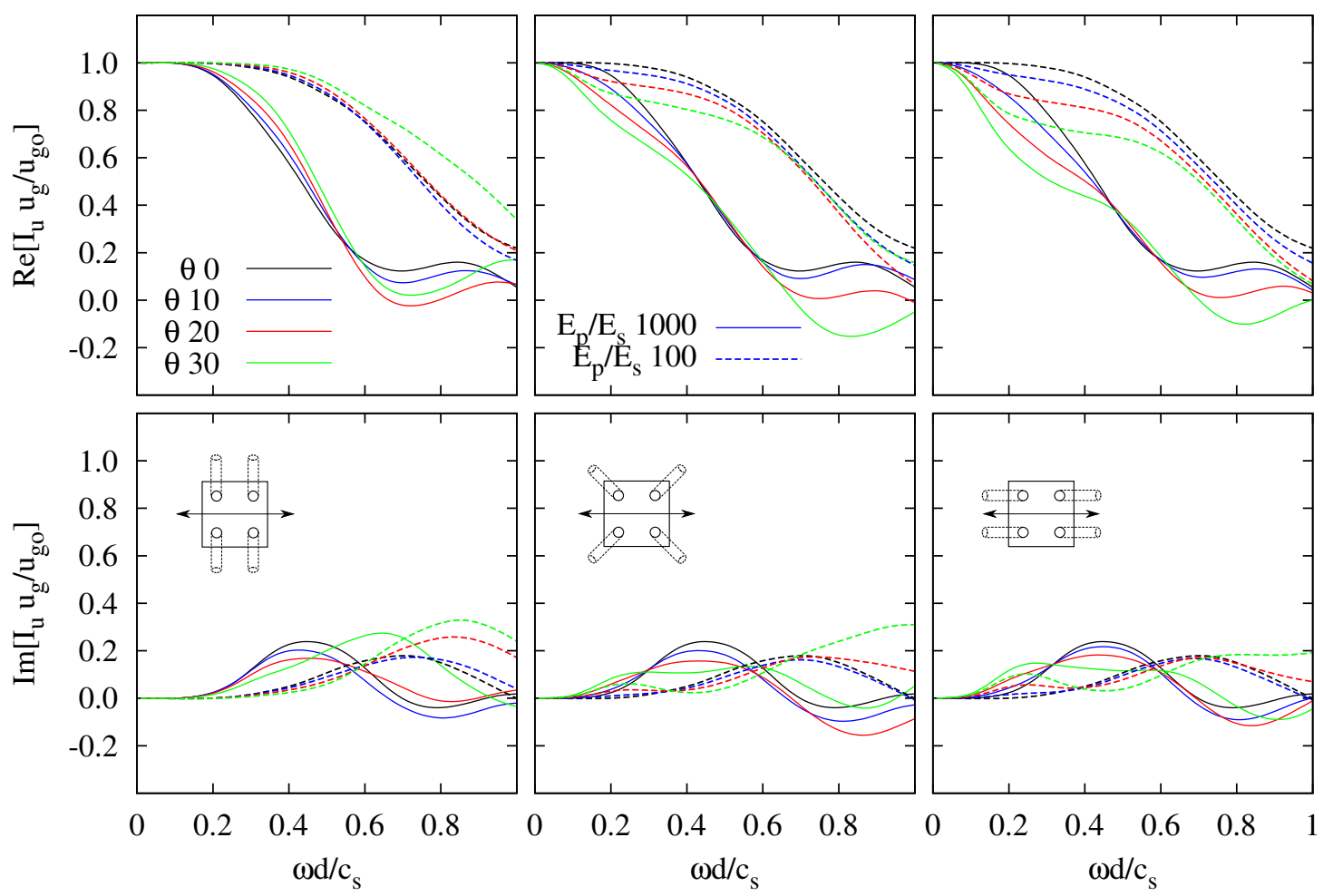

Figure 10: Translational kinematic interaction factor $I_{u}$ of a $2 \times 2$ pile group with battered piles with different rake angles $\theta$ and $s / d=10$. 

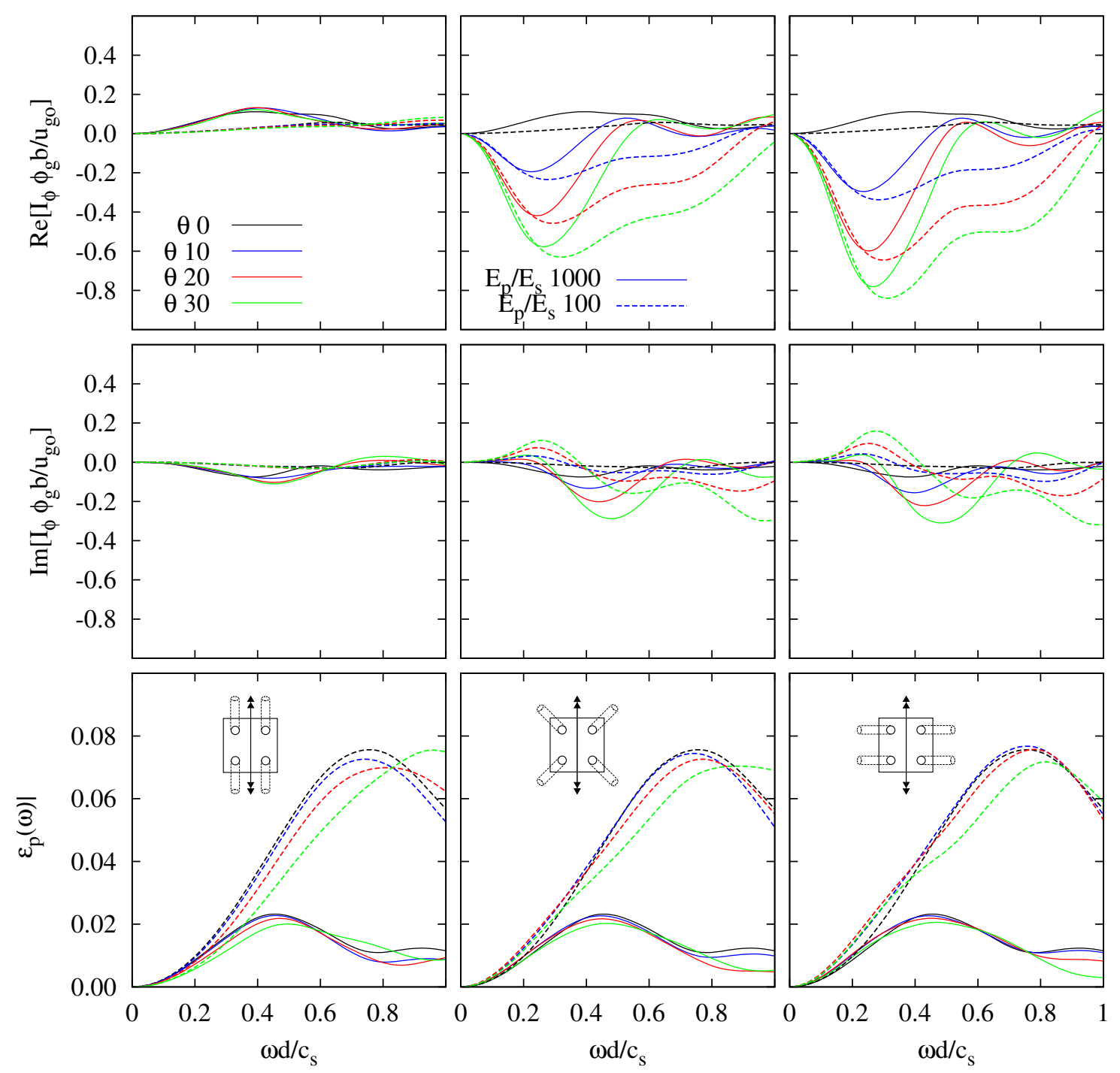

Figure 11: Rotational kinematic interaction factor $I_{\varphi}$ and maximum pile head bending strain $\varepsilon_{p}$ (considering $\left|u_{g_{o}}\right|=1$ ) of a $2 \times 2$ pile group with battered piles with different rake angles $\theta$ and $s / d=10$. 

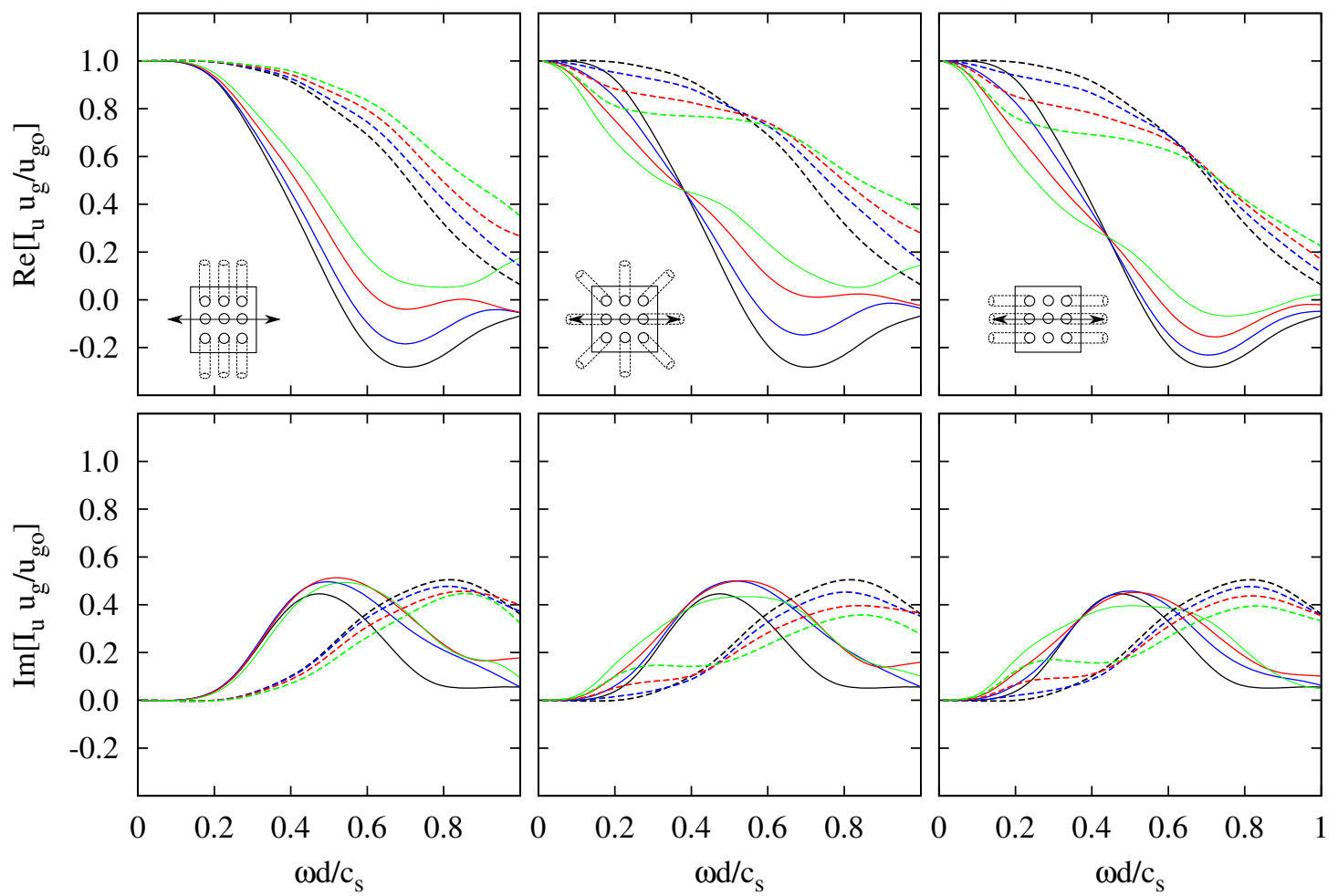

Figure 12: Translational kinematic interaction factor $I_{u}$ of a $3 \times 3$ pile group with battered piles with different rake angles $\theta$ and $s / d=5$.
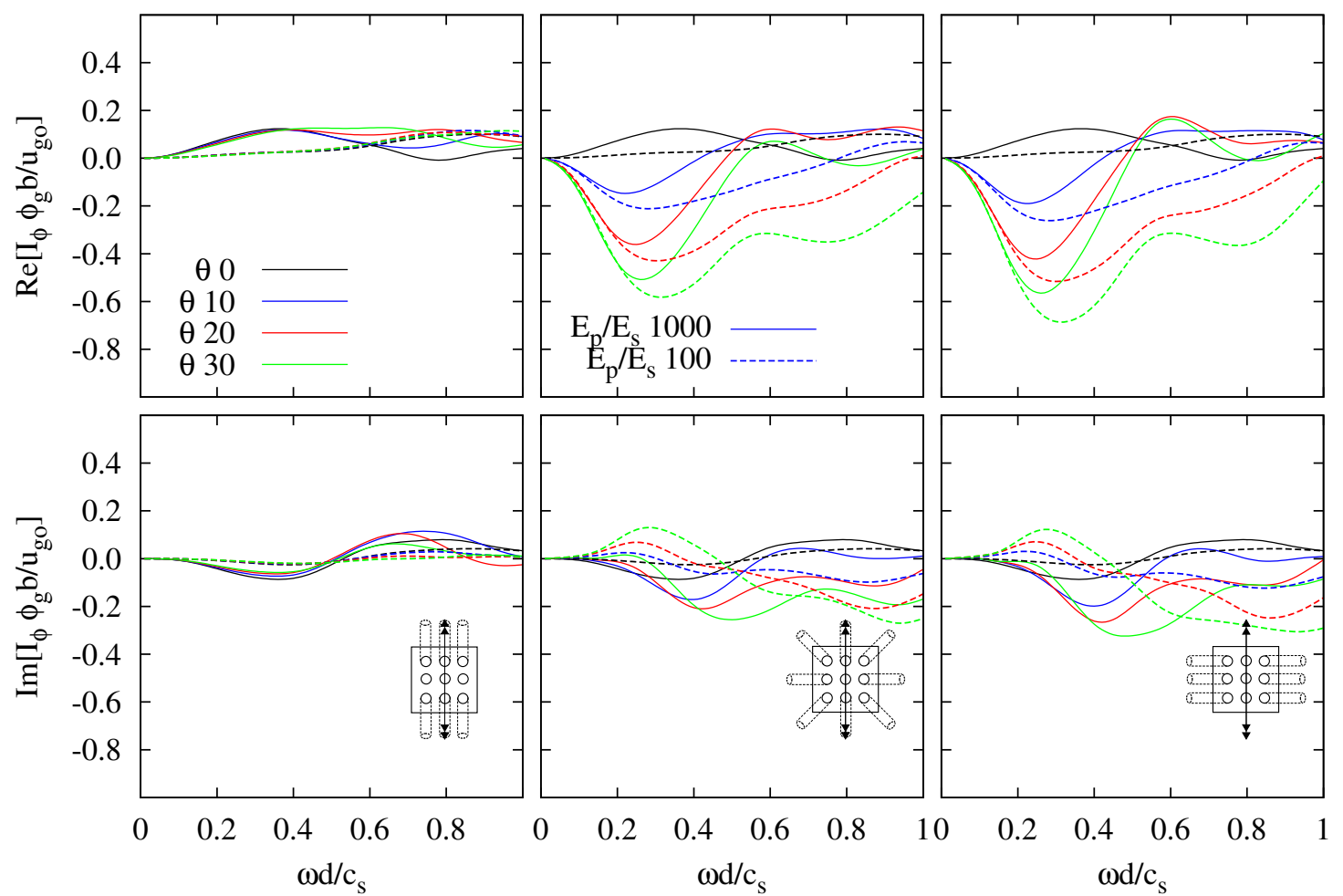

Figure 13: Rotational kinematic interaction factor $I_{\varphi}$ of a $3 \times 3$ pile group with battered piles with different rake angles $\theta$ and $s / d=5$. 


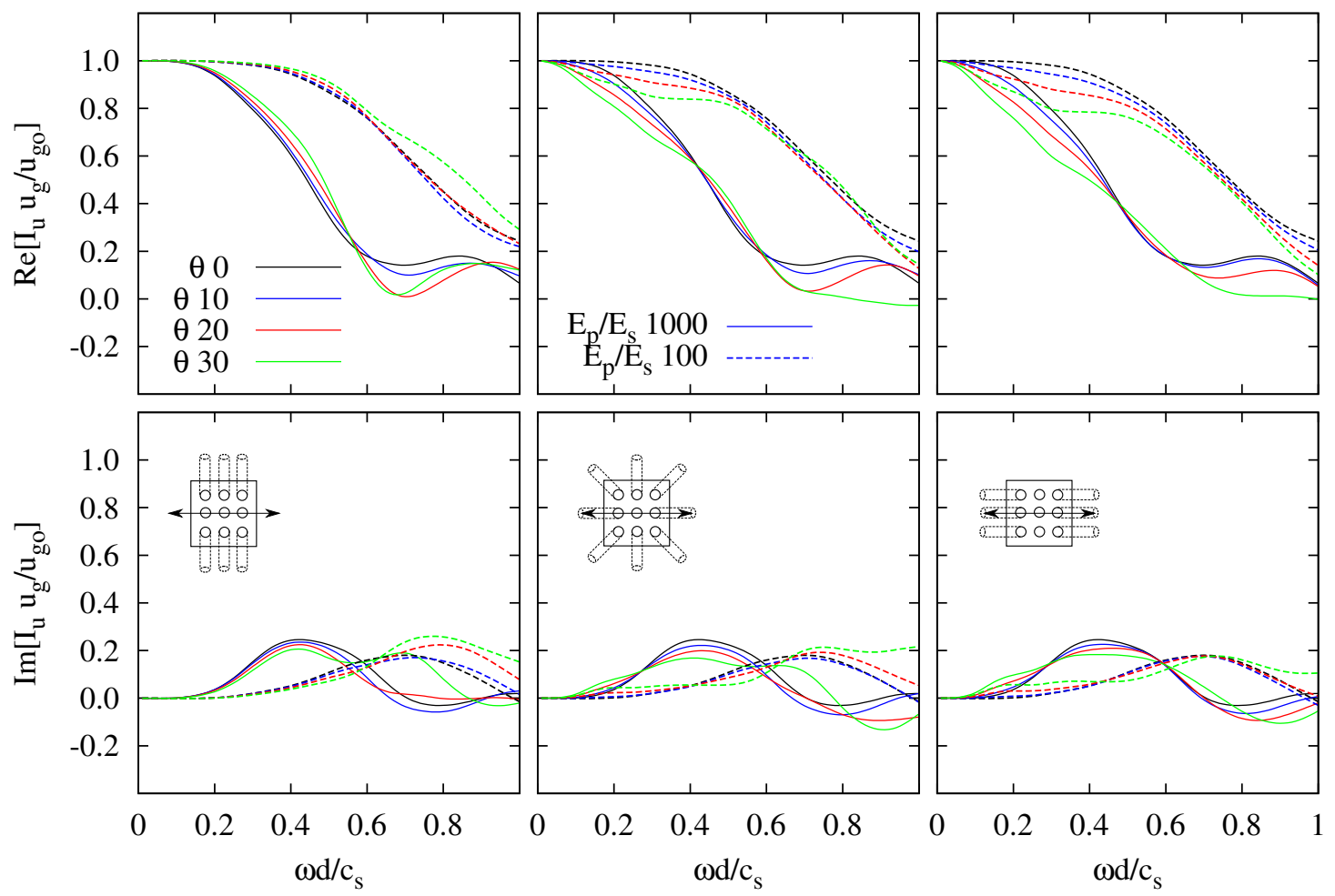

Figure 14: Translational kinematic interaction factor $I_{u}$ of a $3 \times 3$ pile group with battered piles with different rake angles $\theta$ and $s / d=10$.

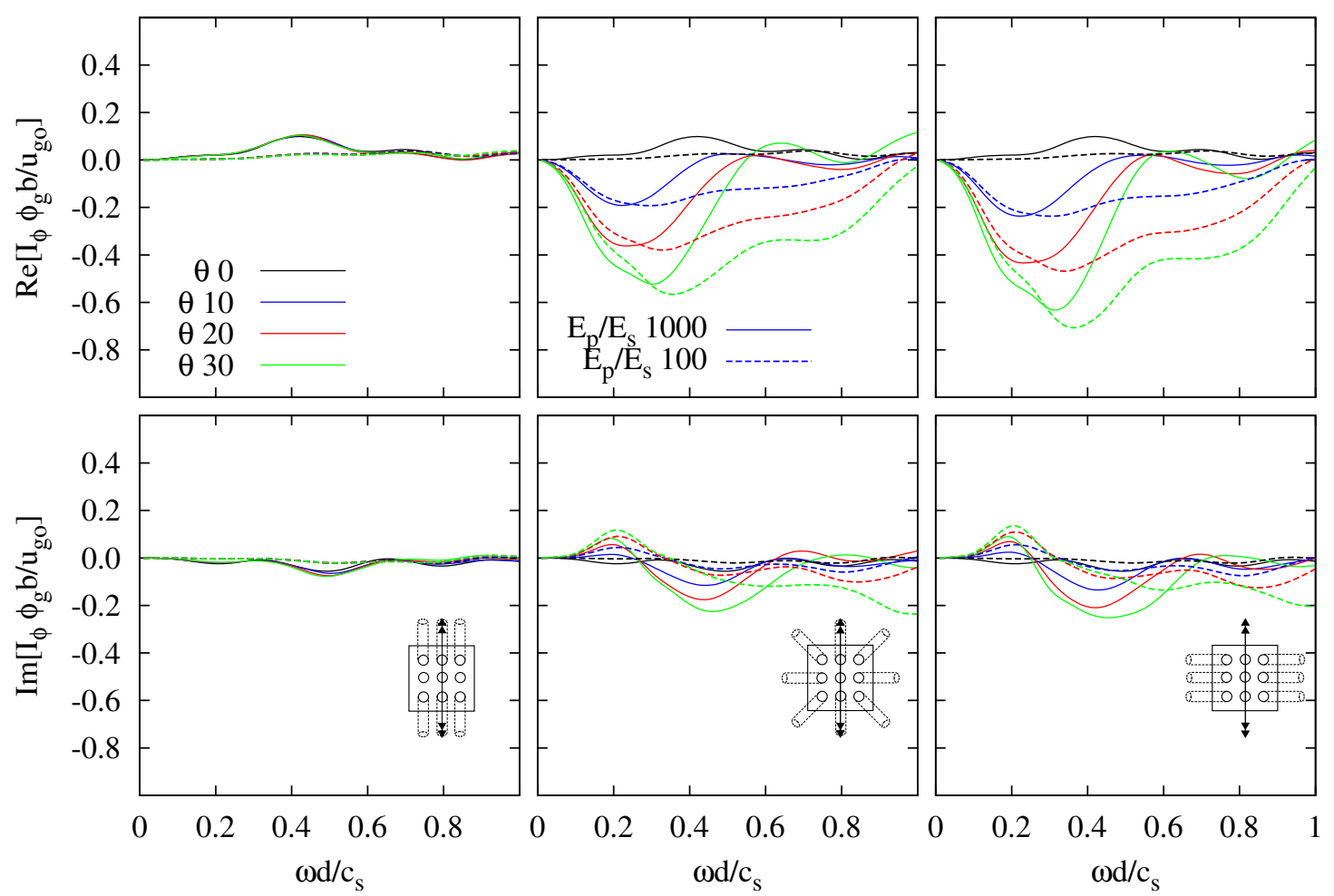

Figure 15: Rotational kinematic interaction factor $I_{\varphi}$ of a $3 \times 3$ pile group with battered piles with different rake angles $\theta$ and $s / d=10$. 

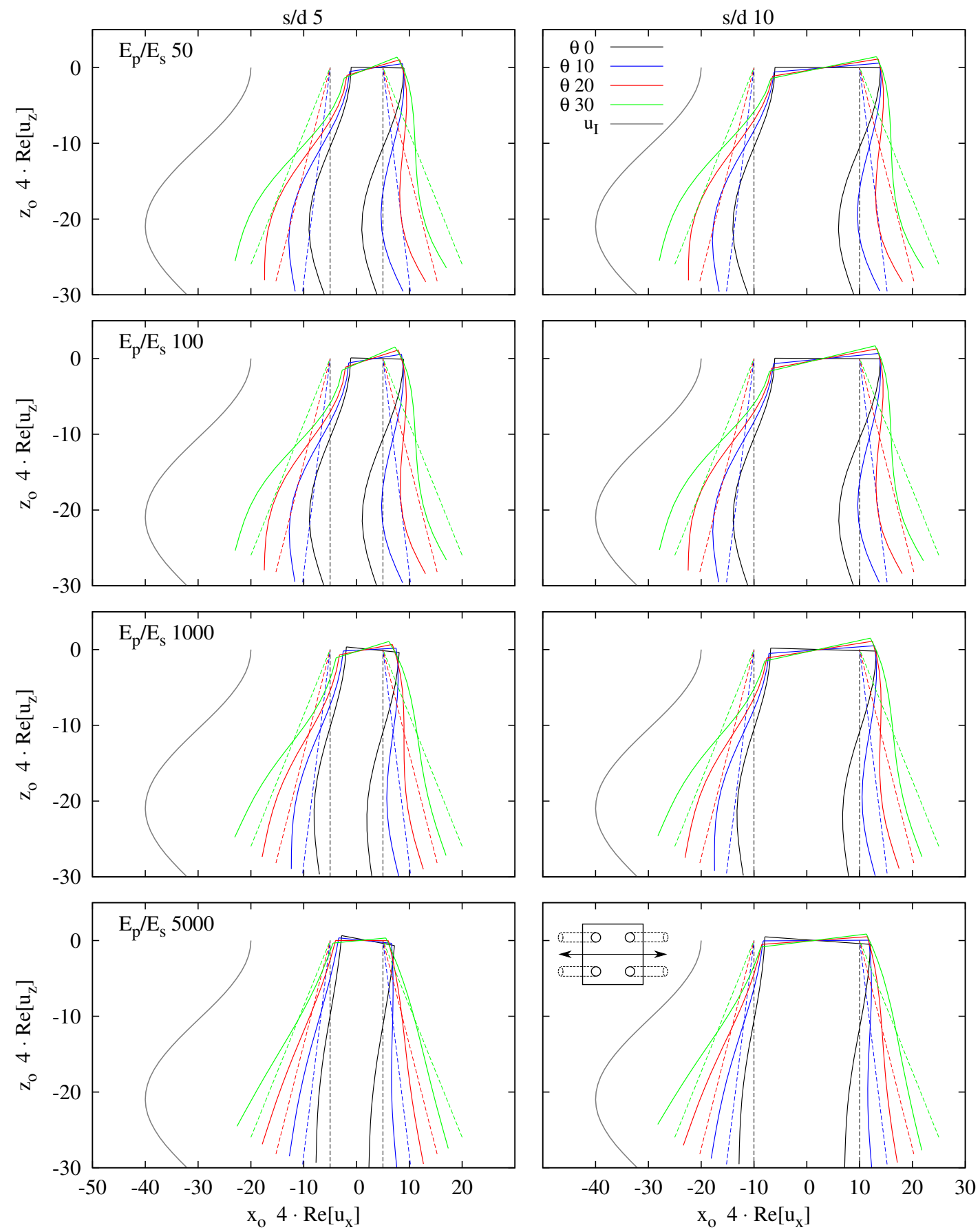

Figure 16: Deformed shape (solid line) and undeformed shape (dash line) of $2 \times 2$ pile groups with battered piles with different rake angles $\theta$ being $s / d=5$ considering $\left|u_{g_{o}}\right|=1$ ( $u_{I}$ displaced 30 units to the left only for illustration purposes). $a_{o}=0.3$ 

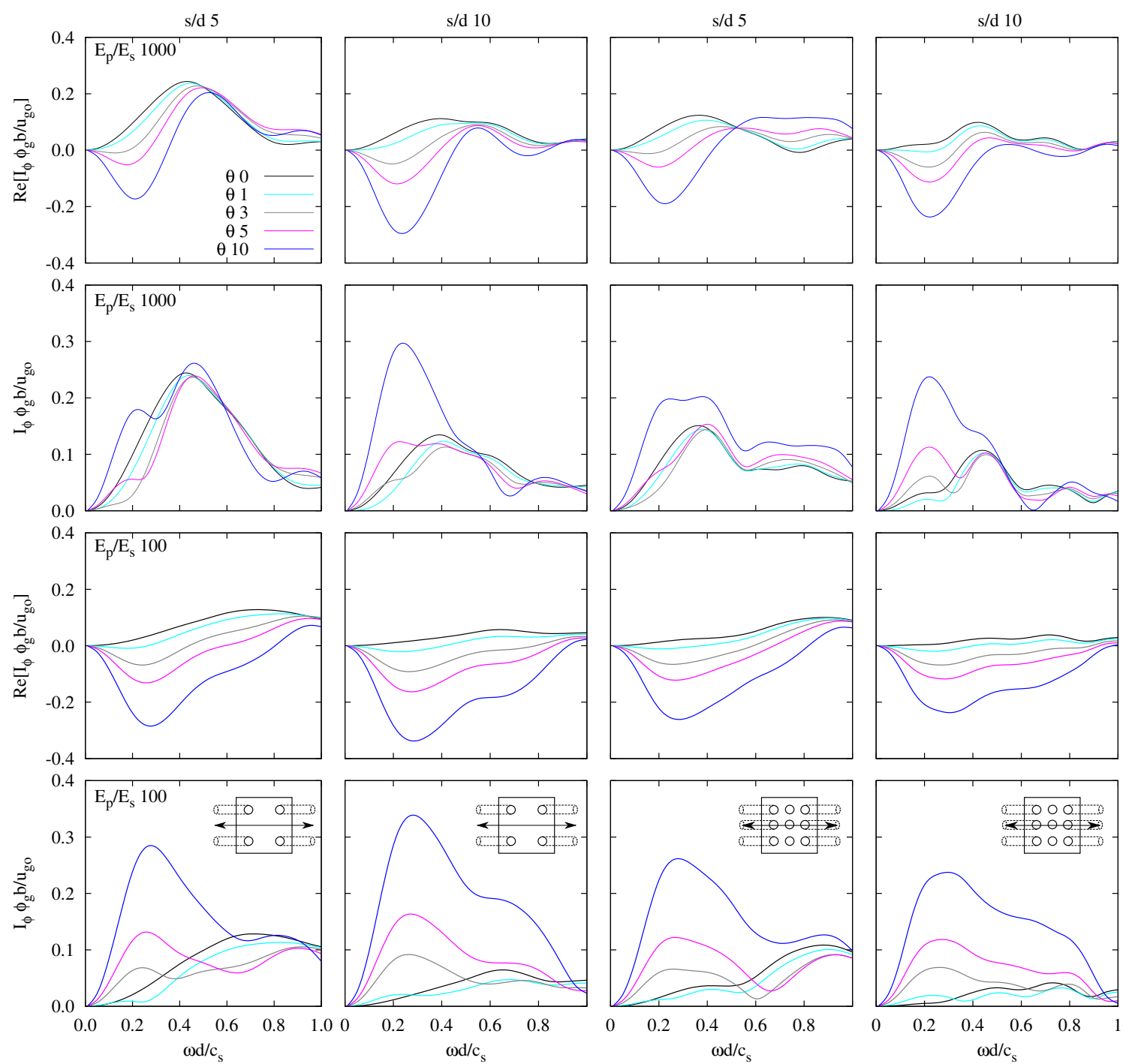

Figure 17: Influence of the rake angle on the rocking motion at the pile cap. 


\section{References}

[1] Poulos HG. Approximate computer analysis of pile groups subjected to loads and ground movements International Journal for Numerical and Analytical Methods in Geomechanics 1999. 23:1021-1041

[2] Poulos HG. Raked piles - Virtues and drawbacks Journal of Geotechnical and Geoenvironmental Engineering 2006. 132(6):795-803.

[3] Deng N, Kulesza R, Ostadan F. Seismic soil-pile group interaction analysis of a battered pile group. In Proceeding of the 4th International Conference on Earthquake Geotechnical Engineering 2007. Thessaloniki, in CD-ROM.

[4] Gazetas G, Mylonakis G. Seismic soil-structure interaction: new evidence and emerging issues. In Geotechnical Earthquake Engineering and Soil Dynamics III ASCE, Geotechnical Special Publication II, 1998; 1119-1174.

[5] Berrill JB, Christensen SA, Keenan RP, Okada W, Pettinga JR. Case study of lateral spreading forces on a piled foundation. Géotechnique 2001; 51(6):501-517.

[6] Guin J. Advances in soil-pile-structure interaction and non-linear pile behavior, Ph.D. Thesis, 1997. State University of New York at Buffalo.

[7] Sadek M, Shahrour I. Three-dimensional finite element analysis of the seismic behavior of inclined micropiles. Soil Dynamics and Earthquake Engineering 2004; 24(6):473-485.

[8] Gerolymos N, Giannakou A, Anastasopoulos I, Gazetas G. Evidence of beneficial role of inclined piles: observations and summary of numerical analyses. Bulletin of Earthquake Engineering 2008; 6(4):705-722.

[9] Gazetas G, Fan K, Tazoh T, Shimizu K, Kavvadas M, Makris N. Seismic pile-groupstructure interaction. Geothec Spec Publ, ASCE 199234 56-93.

[10] Mamoon S M, Ahmad S. Seismic response of pile to obliquely incident SH, SV and P waves. Journal of Geotechnical Engineering 1990; 116:186-204.

[11] Mamoon SM, Banerjee PK. Response of piles and pile groups to travelling SH-waves, Earthquake Engineering and Structural Dynamics 199019 597-610.

[12] Fan K, Gazetas G, Kaynia AM, Kausel E, Ahmad S. Kinematic seismic response of single piles and pile groups. J Geothec Eng Div, ASCE 1991 117(12) 1860-1879.

[13] Kavvadas M, Gazetas G. Kinematic seismic response and bending of free-head piles in layered soil. Geothécnique 199343 207-222.

[14] Kaynia AM, Kausel E. Dynamic stiffness and seismic response of pile groups. Technical Report R83-03, MIT, Cambridge, MA 1982.

[15] Sadek M, Shahrour I. Influence of the head and tip connection on the seismic performance of micropiles. Soil Dynamics and Earthquake Engineering 2006; 26:461-468.

[16] Giannakou AK Seismic behavior of inclined piles, Ph.D. Thesis, 2007. National Technical University of Athens.

[17] Padrón LA, Aznárez JJ, Maeso O. BEM-FEM coupling model for the dynamic analysis of piles and pile groups. Engineering Analysis with Boundary Elements 2007; 31:473-484.

[18] Padrón LA. Numerical model for the dynamic analysis of pile foundations, Ph.D. Thesis, 2009. University of Las Palmas de Gran Canaria. (available for download at http://hdl.handle.net/10553/2841) 
[19] Padrón LA., Aznárez JJ, Maeso O., Santana A. Dynamic stiffness of deep foundations with inclined piles. Earthquake Engineering and Structural Dynamics 2010; 39(12):1343-1367.

[20] Domínguez J. Boundary elements in dynamics. Computational Mechanics Publications \& Elsevier Applied Science: Southampton, NY, 1993.

[21] Maeso O, Aznárez JJ, García F. Dynamic impedances of piles and groups of piles in saturated soils. Computers and Structures 2005; 83:769-782.

[22] Vinciprova F, Maeso O, Aznárez JJ, Oliveto G. Interaction of BEM analysis and experimental testing on pile-soil systems. In Problems in structural identification and diagnostic: General aspects and applications. Springer-Verlag, 2003. pp. 195-227.

[23] Kaynia A M, Kausel E. Dynamics of piles and pile groups in layered soil media. Soil Dynamics and Earthquake Engineering 1991; 10(8):386-401.

[24] Kaynia A M, Novak M. Response of pile foundations to Rayleigh waves and obliquely incident body waves. Earthquake Engineering and Structural Dynamics 1992; 21:303-318.

[25] Mylonakis G Simplified model for seismic pile bending at soil layer interfaces. Soils and foundations 2001; 41(4):47-58. 